\title{
Strangers are Friends I haven't Met Yet: \\ A Positive Approach to Young People's Use of Social Media
}

\author{
Victoria Wang and Simon Edwards
}

\begin{abstract}
ABSRACT
This article reports on a recent research project undertaken in the UK that investigated young people's use of a range of prominent social media tools for socialising and relationship building. The research was conducted by a way of online survey. The findings suggest that this sample of British young people's socialising and relationship building practices via the range of prominent social media tools reflect similar behavioural categories used offline. The use of these social media tools provides young people with an opportunity to manage, simultaneously, different categories of relationships in a multiplicity of 'spaces' created by these tools. The findings challenge the widely held belief that young people expose themselves to risk on social media as they indiscriminately befriend strangers. There is an absence of evidence of 'unjustified' intent to harm others. Indeed the findings indicate a strong desire to primarily support and protect those with whom relationships have been carefully established. The research suggests in fact that online engagement through social media can be positive and constructive for young people. It appears to provide them with a challenging 'space' to practice identity and relationship management strategies.
\end{abstract}

Keywords: youth, social-media, relationships, behaviours, self-identity 


\section{Introduction}

Over the past decade, a number of popular social media tools, including Facebook, Twitter, WhatsApp and Snapchat, have become intrinsic to young people's socialising and relationship building practices (Boyd 2014; Weilenmann, Hillman and Jungselius 2013). Much of media and also academic attention paid to young people's use of social media has focused on the negative and dangerous by emphasising activities that can be placed under the undefined umbrella term of cyberbullying (Davies 2010; Kowalski, Limber and Agatston 2012; Paul, Smith and Blumberg 2012; DfE, 2014). Such attention sometimes unnecessarily over-signifies concepts of risk, and of victim and perpetrator (Tokuma 2010; Ttofi and Farringdon 2011). Cesaroni, Downing and Alvi (2012) have argued that activities adults call 'cyberbullying' may, in fact, be fairly normal to young people. Furthermore, they suggest that current concerns around so-called cyberbullying activities may be classified as a 'moral panic'.

Thus, research that identifies new interpretative frameworks was needed in order to reassess young people's use of social media. It was also needed to arrive at a more complex premise of online socialising and relationship building (Livingstone, Mascheroni and Murru 2011). This research adopts a positive stance in order to investigate how a safer online communicative environment can be developed by a better understanding of current socialising and relationship building practices amongst young people in a range of prominent social media tools. In Wang, Tucker and Rihll (2011), it was argued that the range of social media tools belong to a category of phatic technology - a concept originating in the social linguistics notion of 'phatic communion' (Malinowski, 1923). The primary purpose of a phatic technology was argued to be to establish, develop and maintain human relationships (ibid.). These technologies include: '(i) systems of email; (ii) commercial tools; (iii) social networking tools; (iv) a range of web-based software programs known as social software; and (v) advanced three dimensional virtual worlds created for different social purposes known as cybercommunities' (Wang, Tucker and Rihll 2011, 44). Phatic technology, therefore, is a subset of communications technology, where 'the essence of communication is relationship building not information exchanging' (ibid., 45).

Ultimately, the research aims to devise an interpretive framework based on complex behavioural and relationship dimensions, which underlie young people's communicative practices on social media. This interpretative framework would, in turn, be used to develop a digital relationship management platform which would offer alternatives to 'censoring' 
approaches. Since the Internet along with its various social media tools are here to stay and have an even more significant impact in our lives, any attempt at managing such a highly complex relationship system must be encouraged. It must also be protected in order to provide young people with an environment to practice identity and relationship management strategies.

The first stage of this research project, and indeed the focus of this article, is a quantitative study designed to illuminate some basic contours of young people's socialising and relationship building practices on eight social media tools. The findings suggest that our participants' socialising and relationship building practices on the range of social media tools reflect similar behavioural categories used offline found in (name deleted to maintain the integrity of the review process, 2013). The use of these social media tools provides young people with an opportunity to simultaneously manage different categories of relationships in a multiplicity of 'spaces' created by these tools. Interestingly, our findings challenge the widely held belief that young people expose themselves to risks on social media because they indiscriminately befriend strangers (Livingstone 2013). Additionally, there is also no significant evidence of 'unjustified' intent to harm others. Rather there is a commitment to primarily support or protect those with whom relationships have been carefully established. Our research, in fact, suggests that online engagement through social media can actually be positive and constructive for young people.

\section{Social media - A cause for concern or a space of opportunity?}

Academic research on social media has been wide-ranging and multi-disciplinary (Hercheui 2010). An increasing degree of attention has been paid to the influence of social media in young people's lives (Valkenburg, Schouten and Peter 2005; Ofcom 2008; Boyd 2014; Ofcom 2014). A significant proportion of this research is aimed at activities that can be placed under the umbrella term of cyberbullying. This tends to focus interestingly on the negative and dangerous (Kowalski, Limber and Agatston 2012; Tokuma 2010; Williams and Guerra 2007).

Currently, gender is a focus in cyberbullying research (e.g., Byron, 2008; Livingstone, Haddon, Gorzig and Olafsson 2010; Clipson, Wilson and DuFrene, 2012; Ofcom 2014). For example, Livingstone, Haddon, Gorzig and Olafsson's (2010) research claims that teenage females, more than any other groups, have been cyberbullied via social media tools. Furthermore, they attribute this to exposure. Thus females aged 9-12 use email and instant messaging more than boys; while older females aged 13-16 share more videos, photos and 
music with peers than do boys (ibid.). Earlier research has claimed that females under 16 were more exposed to both risk and danger on social media than males (Byron 2008). This was not because they put themselves at risk but because they were approached by strangers with fake personas (ibid.).

Educational setting is a further issue in cyberbullying research (e.g., Paul, Smith and Blumberg 2010). Here, the pre-assumption is that schools can become the primary tool for socialising outside the family unit for most young people (Ortega-Ruiz and Nunez, 2012). Negative issues, associated with the use of social media identified in schools, emerge primarily from fractured relationships in those settings, which are badly managed by young people (Paul, Smith and Blumberg 2010). In fact, the environment of schools, is, however, an unnatural context within which to develop relationships - since it may naturally lead to the formation of social hierarchies for the purpose of survival (Davies 2009; Ortega-Ruiz and Nunez 2012; Ossie-Owusu 2012). As a result, subsequent interpretations of research findings may be largely skewed - over signifying concepts of risk, victim and perpetrator (Tokuma 2010; Ttofi and Farringdon 2011; Kowalski, Limber and Agatston 2012).

The over emphasis of risk and dangerousness appears to coincide with a more general depiction of social media. This, although not necessarily creating a new moral panic as Cesaroni, Downing and Alvi (2012) claim, certainly induces significant anxiety amongst the general public. According to police figures, ${ }^{1}$ for example, the number of alleged crimes involving Facebook and Twitter had increased by $780 \%$ between 2008 and 2012 (The Guardian 2012). Another example arose from a recent interview, where the Chief Executive of the College of Policing (UK) reported that complaints originating from social media made up at least half of calls passed on to front-line officers. Most of these complaints, of course, concern low-level crime, e.g., insults, abuses and threats (Moore 2014). The internet, certainly, creates complex and novel ways for individuals to interact instantaneously across multiple social media sites. The combination of complexity, novelty, multiplicity and instantaneity may, therefore, naturally breed impulsive behaviours (cf. Hobbs 2011). This interesting combination may also easily lead to misinterpretations of behaviour and intent.

Negative assumptions about online social environments extend as far as Presdee's (2000) 'carnival of crime' thesis, which is based on social structure/alienation theory. For

\footnotetext{
${ }^{1}$ Figures from 29 police forces in England, Scotland and Wales.
} 
Presdee, a great deal of crime occurring in contemporary society reflects the fact that the existing social structure encourages individuals to live 'two lives'. The first life is the 'official' life which is characterised by work and governed by an imposed order. The second life is 'the only true site for the expression of one's true feelings for life' and is 'expressed through the world of excess, obscenity and degradation' (Presdee 2000, 8). The Internet has been identified as 'fast becoming the safe site of the second life of the people' (ibid.). During the course of living in this 'safe site', the boundaries of order are frequently crossed (Wall 2007). Further, many forces unique to the online environment, such as anonymity and lack of physicality have been identified as leading to a weakening of the bond between individuals and their socialising environments online (e.g., Williams, 2003).

The negative assumptions taken about online environments created by social media tools are evident, yet this range of social technologies known as phatic technologies, has been growing rapidly and can be expected to continue to do so. This is because many social conditions that characterise the contemporary world significantly amplify both the human need for, and technical development of, these technologies (Wang, Tucker and Haines 2012, 85). The analysis of phatic technology is in line with earlier conceptions of online social formations. These would be examples of technological change and innovation with the potential ability to turn around the social and cultural decay in contemporary society (e.g., Rheingold 1993). Social media tools, and online communities created by these, can be seen as 'expressions of the modern tension between individuality and community' (Matei 2005, 7). These contexts allow for the simultaneous rise of community bonding and self-expression (Wang, Tucker and Haines 2013).

This simultaneous rise reflects a shift in the contours of identity formation and the way, in contemporary society, we now live our lives. Identity is no longer de facto but de jure - 'the self-constitution of the individual life and the weaving as well as servicing of the network of bonds with other self-constituting individuals' (Bauman 2000, 49). What emerges, according to Giddens, is a highly reflexive self-project. He wrote:

The routines individuals follow, as their time-space paths criss-cross in the contexts of daily life, constitute that life as 'normal' and predictable'. Normality is managed in fine detail within the textures of social activity; this applies equally to the body and the articulation of the individual's involvements and projects $(1991,126)$. 
An individual's identity is formed, following these routines, through knowing who he/she is in relation to what Giddens describes as 'reflexively engaged relationships' with their surroundings and the individuals with whom they regularly interact. Having this in mind, a more positive approach, which investigates young people' socialising and relationship building practices on social media is necessary. That there can be considerable scope for young people to engage in the use of social media for positive purposes should, at least theoretically, be recognised (Livingstone 2013; Ofcom 2014).

\section{Methodology}

A grounded theory approach provides the basis for this empirical study. This methodology is commonly used to develop theory grounded in data, which is systematically gathered and analysed (Strauss and Corbin, 1998). It embodies a sense that the researcher is reflexively thinking about the data while collecting it. It allows concepts and hypotheses to emerge from data in the first stage of empirical work, and to be tested against research findings at the following stage. During our research process, therefore, knowledge about the sociology of young peoples' relationship building in a range of social media tools is, in light of new information, recursively revised. The research process consists of three stages. This includes quantitative and qualitative methodological approaches by way of: (i) surveys, (ii) focus group discussions, and (iii) scenario analyses.

At the first stage, quantitative empirical data was gathered by way of an online survey. The aim was to explore some functional dimensions of young people's social practices, within and outside of the school environment, using a range of eight social media tools. These included (i) Facebook, (ii) Texting, (iii) Instagram, (iv) WhatsApp, (v) Snapchat, (vi) Email, (vii) Twitter, and (viii) Google Hangouts. These were identified, as prominent social media tools used by young people, by head teachers and youth leaders who were involved in our discussions at the beginning of this project. The survey bridges the gap in current research created by the overwhelming focus on the fixed internet. This pays no attention to mobile technologies (Olafsson, Livingstone and Haddon, 2014). The design of the survey was guided by the overarching research question:

How are young people's social behaviours, interactions and relationships managed across a range of social media? 
The subsidiary questions informing the questionnaires were:

1. What was the frequency of use of the eight of social media tools by our respondents?

2. To what extent did our data indicate gender differences in usage of social media tool?

3. To what extent could specific association between social media tools and particular relationship types be identified?

4. Could correlations between behaviour types and relationship categories be also identified?

Two head teachers from two secondary schools and the director of a youth organisation in Sussex were contacted via emails. A covering letter explaining the purpose and process of this research was attached to each of the emails sent. Upon agreeing to participate, these individuals then acted as gatekeepers to maintain their organisations' policies and procedures for child protection and safeguarding throughout the research. They were also asked to obtain pupil consent through the schools' and youth organisation's internal procedures. This covering letters were sent to parents of targeted pupils explaining the research. Upon securing consent, a link to an online questionnaire on Survey Monkey consisting of 21 questions was designed and sent to young people in these three research sites. The questionnaire contained a link to a YouTube video which further detailed and clarified the purpose of the research to those involved.

A range of behavioural categories exploring young people's socialising practices was used in the construction of the survey (Table $1 \& 2$ ). These categories emerged from (name deleted to maintain the integrity of the review process, 2013) research exploring the behavioural dimensions of 300 young people's relationship building strategies in physical locations over 18 months. This range of behavioural category was developed from Bell's (1999) research. It was used to guide this research as our participants came from similar demographic and socioeconomic backgrounds as those found in (name deleted to maintain the integrity of the review process 2013)

(Table 1: Here)

(Table 2: Here)

Questions in this survey were designed to gauge the use of this range of social media tools in different relationship categories (Table 3). A significant proportion of a young person's 
socialising and relationship building practices is intimately centred around school based relationships. School based relationships can however be interpreted as a part of an interconnected network of relations, including parents, other family members, friends located off school sites, friends in the classroom and those in other schools (Table 3). These categories reflect relationships encountered on a routine and daily basis. These according to Giddens (1991), constitute routines of normalcy and support an individual's identity formation. It is within these categories that an individual's identity is constituted (Livingstone and Brake 2010) and social capital developed (Hobbs 2011).

(Table 3: Here)

The link to the survey was sent out at the beginning of July 2014 and closed at the end of September 2014. 686 questionnaires were retrieved, of which 543 were completed. A significant proportion of the remaining questionnaires were half completed with an identical series of questions unanswered towards the second half of the questionnaire. It is possible that groups of young people completing questionnaires in lessons may have run out of time.

The findings reported in this article are of a quantitative nature. It represents a mapping exercise that attempts to illuminate our sample of young people's use of some social media tools. We do not claim, here any robust representative value. A much larger scale research study is needed for that purpose. At this stage, the purpose of our empirical work is to guide our subsequent qualitative explorations.

\section{Main Findings}

(Table 4: Here)

(Table 5: Here)

Our findings show that, on average, the female sample of participants use the range of social media tools more frequently than male participants. This is in line with previous findings that females were more likely than males to use social networking sites (Lenhart, Madden, Macgill and Smith 2007).

(Table 6: Here) 
In relation to a willingness to carry out the six different behavioural categories, using the range of social media tools, with a close friend, the sample of participants, on average, are the most willing to protect, followed by to support; and the least willing to welcome, followed by to build. The data also shows that, on average, the female sample of participants were more willing, than male participants, to carry out all behaviours, except Welcoming.

\section{(Table 7: Here)}

The data shows that, on average, out of the 48 combinations of relationship and behavioural categories, ${ }^{2}$ there are only seven cases of male participants having higher mean scores than female participants. Moreover, five of these are in the behavioural category of Exploring: Parents (R1); Adults (you know but not friends) (R5); School/class mates (R6); New people (R7); and Boy/girl friends (R8). The other two are in the category of Maintaining: Parents (R1); and the category of Protecting: Adults (you know but not friends) (R5). There are two cases where female and male have the same mean scores. These are Maintaining: Adults (you know but not friends) (R5); and Supporting: Adults (you know but not friends) (R5). In the cases of the remaining 39 behaviour/relationship combinations, the data shows that, on average, female participants tend to use the range of social media tools more frequently than male participants.

\subsection{Relationships managed on social media tools}

(Table 8: Here)

Texting is primarily used to communicate with family and close friends (78\% Parents, 63\% Family/brother/sister/cousin, 75\% Close friends). Facebook is mainly used to communicate with friends (59\% Close friends, 56\% Friends (not close); 59\% School/class mates). Snapchat is generally used to communicate with Close friends (42\%), School/class mates (29\%), Boy/girl friends (27\%) and Family (22\%). Instagram is, however, used to communicate with Close friends (29\%) and School/class mates (25\%). Email is used to communicate with family (19\% Parents, 16\% Family/brother/sister/cousin) and Adults (you know but not friends) (15\%). In the case of New people, Facebook (37\%), Texting (18\%) and Instagram (10\%) proved to be the three most popular options. Communication within the following relationship categories

\footnotetext{
${ }^{2}$ Using the range of social media tools to carry out a behavioural category with individuals in a relationship category.
} 
appears largely not to involve this range of social media tools (None): Adults (you know but not friends) (52\%), Boy/girl friends (51\%) and New people (47\%).

\subsection{Behaviours managed on social media tools}

(Table 9: Here)

Welcoming has the highest response across the range of social media tools. This is followed by Building and then Maintaining. Protecting has the lowest response rate. Exploring has the second lowest response rate. Here Twitter, Instagram and Facebook are the most preferred tools for this kind of behaviour. There is a lower use of tools for high risk behaviours (Exploring and Protecting) than for lower risk behaviours (Maintaining, Building, Supporting and Welcoming). For high risk behaviours, however, the more frequently used tools are Twitter (49\%) and Instagram (39\%) for Exploring; and Facebook (29\%) and Texting (32\%) for Protecting.

\subsection{Changes in behaviours in relation to levels of relationships}

(Table 10: Here)

Young people are most willing to use social media tools when Welcoming (75\%), Building (63\%) and Exploring (58\%) existing relationships with Close friends (R3). These are followed by Welcoming (48\%), Building (35\%) and Exploring (35\%) with Boy/girl friends (R8). The

relationship category that they are most prepared to use social media tools when Maintaining is Close friend (R3) (32\%). The relationship category in which they are least willing to use these tools is Adults (you know but not friends) (R5).

\section{Discussion}

In this section, our analysis moves towards a structured discussion, evidenced by data collected, of young people's use of social media tools. The discussion is guided by the following three themes: (i) managing relationships with multiple social media tools, (ii) who am I becoming? and (iii) stranger danger.

\subsection{Managing relationships with multiple social media tools}


Our data indicates that the primary use of nearly all social media tools is to manage and reconstruct positive relationship building behaviours within already existing relationships (Table 8). This coincides with a recent claim that young people are managing existing close circles of established offline relationships online. This results in a re-construction of their offline relationship management strategies across a range of social media tools (e.g., Livingstone, Mascheroni and Murru 2011).

Our findings help clarify this debate and demonstrate that different social media tools are used for different behavioural categories. Our sample of young people, for example, appears to be more willing to use the range of social media tools to welcome (75\%), build $(63 \%)$ and explore (58\%) existing relationships and ties with close friends and boy/girl friends. However, they are noticeably less willing to maintain (32\%) these relationships using these tools (Table 10). This suggests that although the range of social media tools may have become an integral part of young people's online communication, it has not, at least as a first choice, become a mainstream place for their relationship maintenance (cf. Baym 2010). Our data may also reflects wider research findings (e.g., Ellison, Steinfield and Lampe 2011) that young people use social media tools primarily to develop social capital by exploring existing relationships and welcoming people with whom relationships have already been established (Table 8 ). The data also supports research findings that social media tools can provide contexts for managing relationship construction not deconstruction (Christakis \& Fowler 2009; Davies 2010; Sheer 2011).

As discussed in Section 2, however, managing different relationship and behavioural categories, across a range of social media tools, can lead naturally to assumptions about risk which might be generated by misunderstandings. In face-to-face interactions, behaviours of each individual will be located in the same physical site and can be understood within the context of previous behaviours. This provides a relatively smooth transition and flow of behaviours within a given activity. Moving from an offline site to meet someone at another offline site requires, moreover, the physical moving away from one social space to the next, creating the illusion of what Deleuze described as 'scenes within each individual's narrative' (Colebrook 2002). Following these, managing relationships and behaviours across different social media tools requires careful management in order to understand and remember how (i) the overall relationship building strategy across all media is used; and (ii) behaviours on one social media relate to behaviours in another (Tables $8,9 \& 10$ ). 
Yet, we are living in a risk ${ }^{3}$ society, which is characterised by increasingly fractured social sites and relationships (e.g. Beck 1992). Thus, although closely associated with assumptions of risk and danger, managing multi-dimensional relationships and behaviours across a range of social media may also provide young people with a challenging arena to practice relationship management.

\subsection{Who am I becoming?}

Learning how to manage relationships across a range of social media tools also provides opportunities for young people to gain a better understanding of their self-identities. In the physical world, young people may congregate on one site - behaviours, such as Building, Maintaining and Welcoming are all managed within the spatial and observable boundaries of that given space/time framework. However, online time/space frameworks are criss-crossed simultaneously both laterally and longitudinally. Here, there is often (i) a time delay in responses, and (ii) opportunity to see another person's reactions before making a further statement. Therefore, using various forms of social media to manage different behaviours requires an ability to multi-task in order to manage simultaneously the whole relationship management strategy across a range of social media.

What emerges from our findings is a set of conditions within which highly reflexive relationships and a self-project are maintained and engaged. These conditions include behaviours engaged, relationship levels managed, willingness, ability and access to use a range of communicative devices and characters from which to choose to construct sentences on those devices. The reflexive self-project, however, is not, as our evidence shows, managed in isolation from others where the self is autonomous (Tables 7, 8, $9 \& 10$ ). Livingstone, Mascheroni and Murru (2011) suggest:

In relation to social networking, it seems that the task of interpretation is highly focused on the developing self - to borrow Mead's terms (1934), both the 'I' as in, who am I in and for myself, and the 'me' as in, how do others see and respond to me, what community am I part of (3).

\footnotetext{
${ }^{3}$ For Beck (1992), risk can be defined as a systematic way of dealing with risks and insecurities that are characteristic of the contemporary world.
} 
Bauman (2001) suggests that a crisis of 'identity and belonging' has emerged in contemporary societies due to the collapse of communities, rites of passage and traditional structures. Consequently, an individual's identity is now determined by himself/herself (Bauman, 2000). In contemporary society, individuals are 'unfinished projects' (Freire 1970), 'open beings, involved in a continuous process of representation, interpretation and reshaping of reality' (Schipani 1984, 26). Thus, every individual has a creative drive towards a future oriented being. Our findings suggest that young people are more willing to use social media tools when Welcoming, Building and Exploring within existing relationships with close friends and boy/girl friends (Table 10). If we consider the behaviour descriptors (Table 2), each of these behaviours has a future orientation. For some examples, Building pulls individuals together to overcome a situation in order to establish a deeper level of bonding capital within a relationship. Exploring, however, takes into consideration personal risks and safety but with the intent to move towards a new social space or relationship level. Welcoming provides a negotiated transition from one level of relationship towards another. Thus, within this complex web of relationships and behaviours managed on various forms of social media tools, a trust cocoon is built through the maintenance of daily routines. That is, in terms of having a set of language codes and behaviours created via these codes associated with each specific relationship category.

Online or offline, existential questions may be encountered at any given time and space (Taylor 1989). These questions might include: 'Who? (am I, are you, are we), Why? (are you, we, am I here), What? (in my, your, our actions represents Good or Bad)' (ibid, 28). Following our earlier argument, if the self-project is, indeed, future orientated then the question being asked should not simply be 'who am I?'. Rather, it should be 'who am I becoming?'. Moreover, if an individual's self-project is highly reflexive (Giddens 1991) it cannot be made separable from significant others surrounding the individual and relationships that arise from these. It is in the careful management of these relationships that a trust cocoon is nurtured. The question 'who am I becoming?' is, therefore, inseparable from the question 'who are we becoming together?'. One is co-dependent on the other. An individual's self-identity is heavily influenced by other individuals, since subjectivity is derived from inter-subjectivity (Giddens 1991).

Our research demonstrates that Protecting behaviours which 'assertively claim social space, walk away from or exclude a person from a social group' (Table 2) are being conducted primarily between existing relationships (Table 7). The findings also show that Protecting is 
more frequently carried out within the context of close friends (R3) and boy/girl friends (R8) in order to protect the bonding capital established within strong relational ties. This raises the possibility that, if Giddens and Taylor are correct, some online communications that are seen as 'aggressive intent to harm' may well be seen by the perceived perpetrator as protecting not only the close friend or boy/girl friend but also that of the self-project. Also assertive claiming of social space and aggressive intent to harm would be, in this case, justifiable.

\subsection{Stranger danger}

A final theme that has emerged from our findings is that young people are strategically managing risks and potential harms on various social media. Risks and harms on social media are mostly associated with exposure to unknown adults and consequent victimisation (Byron 2008; Walrave and Hiermann, 2011; Livingstone, Mascheroni and Murru 2011).

Developing this theme relating to assertive and aggressive intent in order to maintain and protect the reflexive self-project, Livingstone (2013) claims that the meaning of harm in relation to online risks are often unclear. If risk is a systematic way of dealing with risks, insecurities and dangerousness that are characteristic of the contemporary world, then our findings show the young people are managing, carefully and systematically, hazards and insecurities related to the production of a future orientated self, via using social media tools. In addition to findings (Table 7) that show, for example, Protecting and Exploring are behaviours used to primarily extend and protect existing relationships rather than to explore relationships with new or unknown people via social media tools our findings also demonstrate that:

(i) Facebook is the $4^{\text {th }}$ most frequently used social media tool used to communicate with new people (Table 8) and, at the same time, exploring is the second least frequently engaged behaviour on Facebook (Table 9); and

(ii) Welcoming is the most frequently used behaviour on Facebook (Table 9).

Assessing these findings in combination, it is conceivable that where existing friends are most frequently protected and welcomed, new people may also be welcomed. However, some caution is also exercised before taking the relationship to another level.

Our data also suggests that social media tools are used less frequently in high risk behaviours, such as Exploring new relationships and Protecting people. Thus, only $16 \%$ of our 
participants would explore relationships with new people (Table 10). Furthermore, on average, the sample of male participants explores relationships with new people more frequently than females. This coincides with Benson, Filippaios and Morgan's (2010) research on college students. This showed that females joined social networking sites in order to develop and keep in touch with existing friends. Males, however, joined largely to make new friends.

Evaluating the behaviour of Exploring further, it is clearly a conscious decision to wait (in social space) until the person exploring feels safe and ready to move into another vacant social space or mingle with another group of social peers (Table 2). The concept of Exploring in this research implies, therefore, a careful 'holding' of the relationship until the future goal of inclusion and acceptance into the self-project is made accessible. This may imply again that Protecting and Maintaining the reflexively managed self-project is the primary motivation for Exploring and Protecting behaviours. However, when involved with new relationships and assertive actions, these are widely viewed as high risk behaviours. This coincides with Putnam's (2000) idea that as relationships develop so do trust and stronger bonds. Initially, these relationship ties are (relatively) weak. Their strength lies in their potential as resources to provide opportunities, which in turn support the self-project into the future (cf. Granovetter 1982).

Risk taking, including risk calculation and negotiation, is therefore a condition of contemporary social life that increasingly affects individual lives - especially young lives. If modern features of modern living are reflexively constructed, then protecting relationships within such constructions can be seen by young people as an essential element to their existence.

\section{Conclusion}

At this stage, to summarise, we have found that our participants' relationship building strategies on the range of social media tools reflect similar behavioural categories used offline. We suggest that the use of social media tools provides young people with an opportunity to manage simultaneously different categories of relationship with a multiplicity of tools. More importantly, drawing on theories of modernity, we argue that any attempt at managing such a highly complex relationship system must be encouraged and protected in order to provide young people with a challenging ground to practice relationship management. Based on our findings, we challenge the widely held belief that young people expose themselves to risks on 
social media tools because they indiscriminately befriend strangers. Our data shows no evidence of 'unjustified' intent to harm others. Rather intent is to primarily support or protect those with whom relationships have been carefully established.

It needs to be empathized that this particular stage of our empirical work is a mapping exercise that attempts to illuminate our sample of young people's use of some social media tools. Thus, the specific findings from our analyses do not necessarily represent generalizable trends. A much larger scale research study is needed for that purpose. However, the themes that have emerged may help direct subsequent stages of research into questions directed towards the production and maintenance of the self-project by way of social media tools. Rather than notions of bullying, victimisation and perpetration, based on our current findings, it is likely that activities, commonly interpreted as cyberbullying, are in fact carried out by young people in order to protect themselves. Rather than accepting an assumption that the Internet and its associated technologies create criminogenic environments, subsequent research will address 'how can social technologies, which we identify as phatic technologies, be used to establish, build and maintain better social relationships?'

\section{Notes}

1. This study was supported by Electric Storm Youth, Lancing (Charity No: 1121106, Company No: 6349436) and Sussex Police (Police Property Act Fund Routine Order 29/11). The emerging interpretative framework has enabled practitioners working with young people across the two participating schools and Electric Storm Youth to develop appropriate interventions when issues related to digital social networking arise.

2. One of the authors is a director of Electric Storm Youth and works as a voluntary consultant on youth issues in the local community and in schools across Sussex. 


\section{List of Tables}

Table 1. The two ranges of behavioural and linguistic categories.

The range of behavioural categories includes:

1. Building relationships

2. Maintaining relationships

3. Supporting someone

4. Protecting someone

5. Exploring relationships

6. Welcoming someone

Table 2. The behavioural categories explained (name deleted to maintain integrity of review) 


\begin{tabular}{|c|c|}
\hline Building & $\begin{array}{l}\text { Two or more students pulling together to overcome a situation or complete a task. } \\
\text { Tasks as vehicles for achieving goals where immediate gestures indicated calm, } \\
\text { focused attention with little mutual eye contact. Joking a significant part of this } \\
\text { behaviour between peers; short sentences but mainly full sentences used. }\end{array}$ \\
\hline Maintaining & $\begin{array}{l}\text { Free expression of peers within a group of friends where body language is } \\
\text { presented as open and relaxed working towards a common goal. Immediate } \\
\text { gestures; open, relaxed postures with eye contact, low to medium volume chatter } \\
\text { focusing on social activities. Full sentences primarily. }\end{array}$ \\
\hline Protecting & $\begin{array}{l}\text { Assertive claiming of social space by a person or persons towards peers such that } \\
\text { they affirm themselves and their identity. Medium volume short statements with } \\
\text { arm waving and exaggerated gestures used to make peers aware of danger. } \\
\text { Walking away from threat or turning towards each other. }\end{array}$ \\
\hline Supporting & $\begin{array}{l}\text { Extending support to a peer or peers to help them be themselves. An action } \\
\text { depicting the words 'I accept you.' Calm and relaxed, consistent eye contact or } \\
\text { maintaining spatial position in relation to peers. Words of encouragement to peers } \\
\text { using full sentences. }\end{array}$ \\
\hline Exploring & $\begin{array}{l}\text { Conscious decision to wait (in social space) until you feel safe and ready to move } \\
\text { into another vacant social space or mingle with another crowd of peers. High } \\
\text { volume and excitable statements but slow and deliberate actions. }\end{array}$ \\
\hline Welcoming & $\begin{array}{l}\text { Negotiated invite to peers to join a group or individual creating a sense of } \\
\text { wellbeing ('thumbs up') Huddling together or close contact within personal } \\
\text { space. High volume statements and jokes towards one another with some full } \\
\text { sentences. }\end{array}$ \\
\hline
\end{tabular}

Table 3. The range of relationship categories.

\begin{tabular}{l} 
R1. Parents \\
R2. Family/brother/sister/cousin \\
R3. Close friends \\
R4. Friends (not close) \\
R5. Adults (you know but not friends) \\
R6. School/class mates \\
R7. New people \\
R8. Boy/girl friends \\
\hline
\end{tabular}

Table 4. Research participants (\%).

\begin{tabular}{ll}
\hline Age & $\%$ \\
\hline 11 & 4.1 \\
12 & 13.9 \\
13 & 38.2 \\
14 & 29.7 \\
15 & 12.5 \\
16 & 1.6 \\
\hline Female & 52.8 \\
Male & 47.2 \\
\hline
\end{tabular}

Table 5. Frequencies of social media tools usage (Female vs. Male). 


\begin{tabular}{lll}
\hline & & Mean \\
\hline Facebook & Female & 3.40 \\
& Male & 2.96 \\
\hline Snapchat & Female & 3.20 \\
& Male & 2.13 \\
\hline Instagram & Female & 3.30 \\
& Male & 2.09 \\
\hline WhatsApp & Female & 1.84 \\
& Male & 1.50 \\
\hline Texting & Female & 3.99 \\
& Male & 3.31 \\
\hline Google Hangouts & Female & 1.41 \\
& Male & 1.26 \\
\hline Twitter & Female & 2.01 \\
& Male & 1.63 \\
\hline Email & Female & 2.39 \\
& Male & 2.31 \\
\hline
\end{tabular}

Table 6. Willingness to use social media tools with a close friend in six different behavioural categories (Female vs. Male).

\begin{tabular}{lll}
\hline & & Mean \\
\hline Building & Female & 3.13 \\
& Male & 3.02 \\
\hline Maintaining & Female & 3.65 \\
& Male & 3.27 \\
\hline Protecting & Female & 4.87 \\
& Male & 3.98 \\
\hline Supporting & Female & 4.79 \\
& Male & 3.82 \\
\hline Exploring & Female & 3.22 \\
& Male & 3.04 \\
\hline
\end{tabular}




\begin{tabular}{lll}
\hline Welcoming & Female & 2.83 \\
& Male & 2.96 \\
\hline
\end{tabular}

Table 7. Frequency in using the range of social media tools to carry out six different behavioural categories with eight different relationship categories (Female vs. Male).

\begin{tabular}{llllllll}
\hline & & $\begin{array}{l}\text { Building } \\
\text { (Mean) }\end{array}$ & $\begin{array}{l}\text { Maintaining } \\
\text { (Mean) }\end{array}$ & $\begin{array}{l}\text { Protecting } \\
\text { (Mean) }\end{array}$ & $\begin{array}{l}\text { Supporting } \\
\text { (Mean) }\end{array}$ & $\begin{array}{l}\text { Exploring } \\
\text { (Mean) }\end{array}$ & $\begin{array}{l}\text { Welcoming } \\
\text { (Mean) }\end{array}$ \\
\hline R1 & F & 2.10 & 1.45 & 1.74 & 1.54 & 3.08 & 3.14 \\
& M & 1.78 & 1.52 & 1.66 & 1.51 & 3.17 & 2.73 \\
\hline R2 & F & 2.25 & 1.63 & 2.01 & 1.89 & 3.16 & 3.47 \\
& M & 1.82 & 1.42 & 1.80 & 1.62 & 3.10 & 2.85 \\
\hline R3 & F & 4.09 & 3.11 & 2.87 & 3.21 & 3.81 & 4.39 \\
& M & 3.36 & 2.04 & 2.25 & 2.26 & 3.39 & 3.64 \\
\hline R4 & F & 2.72 & 1.74 & 2.24 & 2.31 & 2.67 & 3.40 \\
& M & 2.28 & 1.47 & 1.95 & 1.78 & 2.61 & 2.87 \\
\hline R5 & F & 1.41 & 1.23 & 1.55 & 1.35 & 1.85 & 2.1 \\
& M & 1.39 & 1.23 & 1.58 & 1.35 & 2.10 & 2.03 \\
\hline R6 & F & 2.71 & 1.70 & 2.18 & 2.07 & 2.37 & 3.13 \\
& M & 2.52 & 1.57 & 1.98 & 1.76 & 2.72 & 2.89 \\
\hline R7 & F & 1.82 & 1.31 & 1.77 & 1.66 & 1.98 & 2.45 \\
& M & 1.68 & 1.22 & 1.70 & 1.46 & 2.16 & 2.24 \\
\hline R8 & F & 2.54 & 2.05 & 2.11 & 2.21 & 2.62 & 3.15 \\
& M & 2.35 & 1.80 & 1.81 & 1.82 & 2.75 & 3.00 \\
\hline
\end{tabular}

Table 8. How do you communicate with the following people?

\begin{tabular}{lllllllll}
\hline \multicolumn{1}{c}{$\%$} & $\mathrm{R} 1$ & $\mathrm{R} 2$ & $\mathrm{R} 3$ & $\mathrm{R} 4$ & $\mathrm{R} 5$ & $\mathrm{R} 6$ & $\mathrm{R} 7$ & $\mathrm{R} 8$ \\
\hline Facebook & 14.8 & 35.5 & 59.2 & 55.5 & 23.0 & 58.8 & 37.0 & 36.0 \\
Snapchat & 3.1 & 17.9 & 42.3 & 21.9 & 2.4 & 29.1 & 8.8 & 27.3 \\
Instagram & 2.3 & 11.3 & 28.6 & 18.7 & 2.7 & 24.6 & 10.1 & 18.2 \\
WhatsApp & 7.4 & 8.0 & 11.1 & 5.1 & 2.1 & 9.7 & 2.6 & 9.5 \\
Texting & 78.0 & 63.2 & 74.8 & 35.2 & 21.5 & 45.0 & 17.7 & 42.0 \\
Google Hangouts & 2.1 & 2.9 & 3.9 & 1.6 & 1.5 & 3.2 & 1.6 & 5.0 \\
Twitter & 2.1 & 4.3 & 8.4 & 3.9 & 2.7 & 6.4 & 5.5 & 6.8 \\
Email & 18.5 & 16.4 & 10.5 & 4.8 & 15.4 & 7.4 & 3.9 & 7.7 \\
None & 20.4 & 21.1 & 9.7 & 18.2 & 51.6 & 16.4 & 46.5 & 50.8 \\
\hline
\end{tabular}


Table 9. Some of us use different social media tools for different purposes. What do you use each of these for?

\begin{tabular}{lllllll}
\hline \multicolumn{1}{c}{$\%$} & $\begin{array}{l}\text { Buildin } \\
\mathrm{g}\end{array}$ & $\begin{array}{l}\text { Maintainin } \\
\mathrm{g}\end{array}$ & Protecting & $\begin{array}{l}\text { Supportin } \\
\mathrm{g}\end{array}$ & $\begin{array}{l}\text { Explorin } \\
\mathrm{g}\end{array}$ & $\begin{array}{l}\text { Welcomin } \\
\mathrm{g}\end{array}$ \\
\hline Facebook & 76.7 & 58.6 & 28.5 & 39.1 & 33.4 & 81.2 \\
Snapchat & 52.7 & 58.8 & 15.9 & 30.2 & 17.7 & 67.9 \\
Instagram & 35.7 & 46.4 & 21.1 & 23.2 & 38.6 & 62.1 \\
WhatsApp & 68.9 & 47.8 & 22.4 & 27.3 & 14.9 & 56.5 \\
Texting & 83.8 & 59.6 & 32.4 & 41.5 & 14.3 & 67.3 \\
Google Hangouts & 42.1 & 39.0 & 21.1 & 21.1 & 21.1 & 40.0 \\
Twitter & 37.0 & 34.1 & 22.5 & 23.2 & 48.6 & 47.8 \\
Email & 41.7 & 22.7 & 19.0 & 18.6 & 12.4 & 62.8 \\
\hline
\end{tabular}

Table 10. Extent of willingness to use social media tools in different types of relationship categories.

\begin{tabular}{lllllllll}
\hline \multicolumn{1}{c}{$\%$} & R1 & R2 & R3 & R4 & R5 & R6 & R7 & R8 \\
\hline Building & 14.8 & 12.2 & 63.3 & 24.6 & 5.7 & 28.1 & 8.9 & 34.6 \\
Maintaining & 7.2 & 6.1 & 32.0 & 7.4 & 3.4 & 7.7 & 3.2 & 18.7 \\
Protecting & 9.9 & 12.8 & 28.2 & 14.8 & 8.0 & 13.6 & 9.8 & 16.7 \\
Supporting & 6.9 & 8.9 & 33.1 & 14.4 & 4.5 & 10.6 & 6.4 & 19.8 \\
Exploring & 44.0 & 43.1 & 57.6 & 26.8 & 13.4 & 23.9 & 16.2 & 35.4 \\
Welcoming & 39.5 & 46.0 & 74.5 & 44.9 & 13.5 & 35.7 & 21.1 & 48.2 \\
\hline
\end{tabular}

\section{References:}

Bauman, Z. 2000. Liquid Modernity. Cambridge: Polity Press.

Bauman, Z. 2001. Community: Seeking Safety in an Insecure World. Cambridge: Polity Press.

Baym, N. 2010. Personal Connections in the Digital Age. Cambridge: Polity Press.

Beck, U. 1992. Risk Society: Towards a New Modernity. London: Sage Publications.

Bell, J. 1999. Doing your Research Project. Open University Press, Buckingham. Philadelphia. Benson, V., Filippaios, F., \& Morgan, S. (2010). Online social networks: Changing the face of business education and career planning. International Journal of E-Business Management, 4(1), 20-33. 
Bourdieu, P., \& Wacquant, L. 1992. An Invitation to Reflexive Sociology. Chicago: University of Chicago Press.

Boyd, D. 2014. It's Complicated: the Social Lives of Networked Teens. Yale University Press. Byron, T. 2008. Safer Children in a Digital World: The Report of the Byron Review. London: Department for Children, Schools and Families, and the Department for Culture, Media and Sport.

Cesaroni, C., Downing, S. and Alvi, S. 2012. "Bullying Enters the 21st Century? Turning a Critical Eye to Cyberbullying Research." Youth Justice 12(3): 199-211.

Christakis, N., and Fowler, J. 2009. “Connected: The Surprising Power of our Social Networks and How they Shape our Lives.” Little, Brown: New York.

Cohen, S. 1972. Folk Devils and Moral Panic. London: MacGibbon and Kee Ltd.

Colebrook, C. 2002. Gilles Deleuze. Oxford: Routledge.

Davies, M. 2010. Children, Media and Culture (Issues in Cultural and Media Studies). Berkshire: Open University Press.

Davies, R. 2009. "The Affirmation of Ordinary Life: Curricula Structure for Home Education." Unpublished conference paper presented at the British Educational Research Association Conference.

DfE. 2014. Preventing and Tackling Bully Advice for Head Teachers, Staff and Governing Bodies. DfE Publications.

(Name deleted to maintain the integrity of the review process, 2013). "The Social Construction of Pupils' Cultural Worlds: Negotiating Viable Selves From the Margin." $\mathrm{PhD}$ thesis, University of Sussex.

Ellison N., Steinfield C., \& Lampe, C. 2011. "Connection Strategies: Social Capital Implications of Facebook Enabled Communication Practices." New Media and Society 13(6): 873-892.

Freire, P. 1970. Pedagogy of the Oppressed. Harmonsworth: Penguin.

Giddens, A. 1991. Modernity and Self-Identity. Cambridge: Polity Press.

Granovetter, M. 1982. "The strength of weak ties: A network theory revisited." In $P . V$. Mardsen \& N. Lin (Eds.), Social Structure and Network Analysis (pp. 105-130). Thousand Oaks, CA: Sage Publications.

Hobbs, R. 2011. Digital and Media Literacy: Connecting Culture and Classroom. Corwin. Kowalski, R., Limber, S., and Agatston, P. 2012. Cyberbullying : Bullying in the Digital Age. Chichester: Wiley Blackwell. 
Lenhart, A., Madden, M., Macgill, A., and Smith, A. 2007. Teens and Social Media: The use of Social Media Gains a Greater Foothold in Teen Life as they Embrace the Conversational Nature of Interactive Online Media. Pew Internet and American Life Project.

Livingstone, S. 2013. "Online Risk, Harm and Vulnerability: Reflections on the Evidence Base for Child Internet Safety Policy.” zer 18(35): 13-28.

Livingstone, S., and Brake, D. 2010. "On the Rapid Rise of Social Networking Tools: New Findings and Policy Implications." Children \& Society 24(1): 75-83.

Livingstone, S., Haddon, L., Gorzig, A., and Olafsson, K. (2010). Risks and safety for children on the internet: the UK report: Full findings from the EU Kids Online survey of UK 9-16 year olds and their parents. EU Kids Online.

Livingstone, S., Mascheroni, G., and Murru, M.F. 2011. "Social Networking among European Children: New Findings on Privacy, Identity and Connection.” Hermes 59: 89-98. [in French]. Lupton, D. 2013. Risk: Second Edition (Key Ideas). London: Routledge.

Matei, S. A. 2005. "From Counterculture to Cyberculture: Virtual Community Discourse and the Dilemma of Modernity." Journal of Computer-Mediated Communication 10(3): article 14. Malinowski, B. (1923) “The Problem of Meaning in Primitive Languages.” In The Meaning of Meaning edited by Charles K. Ogden, C, K., and Ian A. Richards, 146-152. London: Routledge. Moore, K. (2014) 'Social media 'at least half' of calls passed to front-line police". BBC Radio 4's Law in Action, 24 June 2014.

Ofcom. 2008. Social Networking: A Quantitative and Qualitative Research Report into Attitudes, Behaviours and Use.

Ofcom. 2014. Adults'Media Use and Attitudes Report 2014.

Olafsson, K,. Livingstone, S., \& Haddon, L. (2014) “Children's Use of Online Technologies in Europe: A Review of the European Evidence Base.” EU Kids Online network.

Paul, S., Smith, P., and Blumberg, H. 2010. "Addressing Cyberbullying in School Using the Quality Circle Approach.” Australian Journal of Guidance \& Counselling 20 (2): 157-168.

Paul, S., Smith, P., and Blumberg, H. 2012. "Comparing Student Perceptions of Coping Strategies and School Interventions in Managing Bullying and Cyberbullying Incidents." Pastoral Care in Education 30(2): 127-146.

Presdee, M. 2000. “Cultural Criminology and the Carnival of Crime.” Routledge.

Rheingold, H. 1993. The Virtual Community: Homesteading on the Electronic Frontier. New York: Addison-Wesley.

Schipani, D. 1984. Conscientization and Creativity: Paulo Freire and Christian Education. University Press of America. 
Sheer, V. 2011. “Teenagers' Use of MSN Features, Discussion Topics, and Online Friendship Development: The Impact of Media Richness and Communication Control." Communication Quarterly 59(1): 82-103.

Strauss, A. and Corbin, J. 1998. Basics of Qualitative Research: Techniques and Procedures for Grounded Theory. London, Sage.

Tokuma, R. 2010. "Following you Home from School: A Critical Review and Synthesis of Research on Cyberbullying Victimization.” Computes in Human Behaviour 26(3): 277-287.

Ttofi, M. M., and Farrington, D. P. 2011. "Effectiveness of School-based Programs to Reduce Bullying: A Systematic and Meta-analytic Review." Journal of Experimental Criminology 7: 27-56.

Valkenburg, P.M., Schouten, A.P., and Peter, J. 2005. “Adolescents' Identity Experiments on the Internet." New Media \& Society 7(3): 383-402.

Wall, D. 2007. Cybercrime. Polity Press.

Walrave, M. and Hierman, W. 2011. "Cyberbullying: Predicting Victimisation and Perpetration." Children \& Society 25(1): 59-72.

Wang V., Tucker, J.V., and Rihll, T. 2011. "On Phatic Technologies for Creating and Maintaining Human Relationships.” Technology in Society 33(1): 44-51.

Wang, V., Tucker, J.V., and Haines, K. 2012. "Phatic Technology in Modern Society." Technology in Society 34(1): 84-93.

Wang, V., Tucker, J.V., and Haines, K. 2013. "Viewing Cybercommunities through the Lens of Modernity: The Case of Second Life." International Journal of Virtual Communities and Social Networking 5(1): 75-90.

Weilenmann, A., Hillman, T. and Jungselius, B. 2013. "Instagram at the Museum: Communicating the Museum Experience through Social Photo Sharing." In CHI '13 Proceedings of the SIGCHI Conference on Human Factors in Computing Systems. New York: ACM.

Williams, M. 2003. "Virtually Criminal: Deviance, Harm and Regulation within an Online Community." PhD dis., University of Cardiff.

Williams, K., and Guerra, N. 2007. "Prevalence and Predictors of Internet Bullying." Journal of Adolescent Health. 41(6 supp11): S14-S21. 